\title{
Suggestions on China's Ability to Resist External Risk : Based on the Rural Perspective
}

\author{
Lei Zhang ${ }^{1}$, Li Li $^{1,2,3, *}$, Lei Xiao ${ }^{4}$
}

1. Pan-Asian business school, Yunnan Normal University, Kunming 650092, China

2. Yunnan Association for Promotion of Trans-Asian Financial Cooperation and Development,

Kunming 650092, China

3. Champion \& Casualty insurance Co.,Ltd., Kunming 650228, China

4. School of Marxism Studies, Kunming University, Kunming 650092, China

\section{中国抵御外部风险能力建议:基于农村角度 \\ 张雷 ${ }^{1}$, 李丽 ${ }^{1,2,3, *}$, 肖否 ${ }^{4}$ \\ 1、云南师范大学泛亚商学院, 昆明 650092 , 中国 \\ 2、云南省泛亚金融合作发展促进会，昆明 650092，中国 \\ 3、诚泰财产保险股份有限公司，昆明 650228, 中国 \\ 4、昆明学院马克思主义学院, 昆明 650092, 中国}

\begin{abstract}
In recent years, the Central Committee of the Communist Party of China has been calling for systematic risk prevention. especially in the current situation of great power trade frictions, insufficient global economic dynamics and violent international turbulence. We should seriously think about how China should deal with the changing external risks in the future. In the ten years of the economic crisis, how can China survive the crisis from the perspective of rural development? First, it describes the impact of the economic crisis, followed by the crisis crossing and the policy analysis, so as to explain the role of the rural development on the economic crisis, and finally put forward the suggestion of China's ability to resist external risk: Firstly, we should be conscious of the

作者简介: 张雷 (1990-), 男, 陕西咸阳人,

硕士。研究方向: 管理学、应用经济学。 *通讯作者: 李丽 (1980-), 女, 湖北襄阳人, 博士后, 副教授, 研究方向: 旅游经济管
\end{abstract} importance of the countryside; secondly, we should continue to strengthen the right Finally, we should continue to make up for the shortage of rural development and reduce the instability of rural areas.

Keywords : Economic crisis; Rural development; External risk.

\section{摘要}

近几年中共中央不断要求防范系统性风 险, 尤其在今天大国贸易摩擦不断, 全球经济 动力不足以及国际局势剧烈动荡的形势下, 我 们应该认真思考中国未来应该如何应对瞬息 万变的外部风险。正值经济危机十年可从农村 发展角度思考中国如何渡过危机? 首先叙述 经济危机产生的影响, 其次是危机渡过和政策 分析, 从而说明农村发展对面对经济危机的作 用, 最后提出中国抵御外部风险能力的建议: 首先, 我们从意识上对农村的重要性要有清醒 认识; 其次, 我们应该继续加强对农村的投入; 最后, 我们要不断补足农村发展短板和减少农 村不稳定因素。

关键词：经济危机；农村发展；外部风险 


\section{1. 引言}

中共十九大提出了既要全面建成小康社 会、实现第一个百年奋斗目标, 又要乘势而上 开启全面建设社会主义现代化国家新征程, 向 第二个百年奋斗目标进军。中国发展的任何目 标都是以国家经济发展社会稳定为前提, 随着 中国经济实力和综合国力不断提升, 市场开放 程度不断提高, 中国外部环境日益复杂。国际 环境对中国的影响也日趋明显, 4 月中美贸易 摩擦对中国经济的影响很大股市持续走低, 还 有美国精确打击叙利亚, 这些对世界政治和经 济都产生了重要影响, 这就是真实的世界, 中 国随时可能面临这种巨大的外部影响, 应为中 国应对这种外部风险的能力做出思考, 2008 年中国面临不亚于 29、33 大危机, 对如何半 年实现 V 形反弹恢复社会平稳发展的原因探 索, 然后从此角度为未来提供一些思路来应对 这类重大影响, 避免中国发展发生大的风险 [1]。

\section{2. 文献回顾}

马永强、孟子平 (2009) 基于 “外部冲击 $\rightarrow$ 企业缓冲能力 $\rightarrow$ 经济后果” 视角分析了 企业带来了冲击, 说明金融危机如何给企业造 成二个方面的影响, 从微宏两个方面提出缓解 企业的外部冲击 [2]。张佳、张 宏（2009） 从农村劳动力转移的主流遭遇经济危机, 大量 原本外出务工的农民由于城市企业破产、倒 闭, 不回到自己的家乡, 介绍了当前农村劳动 力转移的路径选择, 并提出了一些促进措施 [3]。张车伟、王智勇（2009）2009 年上半年 中国将面临 21 世纪以来最为严峻的就业形 势, 农民工的结构性失业问题突出, 估计约有 多达 3481 万左右的农民工面临着结构性失 业的风险, 最后指出政策的着眼点应该放在如 何促进就业岗位和人员之间的匹配上，对农民 工的培训也将起到积极的效果, 对农民工失业 的严重性和解决就业提供了一些新的思路 [4]。叶冬松 (2009) 国际金融危机对实体经 济的影响不断加深, 全球经济增长减速与我国 周期性调整因素叠加重合, 短期问题与长期矛 盾相互交织, 使经济发展面临的形势异常复 杂。最后面对新的形势、新的挑战, 必须以 科学发展观为指导, 在积极借鉴国内外实践经 验、深入分析国情的基础上, 积极探索扩大内
需的有效途径与方式, 为我们解决经济危机提 供了重要的思考方向 [5]。杨帅、董篠丹、温 铁军 (2014) 农村基础设施投入对于国家和社 会的正外部性; 加上农业收益低下和农村去组 织化的现实, 使得当前农村基础设施建设与维 护面临着劳动力投入的机会成本高、政府与农 户的交易成本高以及地方财政投资意愿低、农 民参与和配合意愿低的困境。思考如何建立农 村基础设施投资的长效机制, 为我们说明了国 家基础设施建设的意义和遇到问题如何解决 [6]。马川（2009）从由美国次贷危机引发的 全球性金融危机, 中国大陆的经济发展受到严 重的冲击, 国家把扩大消费需求作为促进经济 增长的基本立足点。“家电下乡” 正是在这种 特殊情况下, 由财政部, 商务部在反复调查研 究基础上提出的。目的在于通过这样的措施刺 激内部需求, 提升整体经济效益, 同时对农村 地区信息化建设产生促进作用 [7]。温铁军 （2009）通过论述 “三农” 问题在我国长期占 据重要的位置的原因, 化解 “三农” 问题的各 种政策梳理, 还有宏观方面的四点分析三点说 明政策可以解决问题, 最后指出维护农村劳动 力蓄水池关乎稳定大局, 说明了农村问题的重 要性以及对于稳定的意义 [8]。董篠丹、梁汉 民、区吉民、温铁军（2015）三农与 “三治” 作为国家综合性安全的基础而具有准公共品 性质。农村政策思想要以国家安全为目标, 运 用整体性视角, 统筹协调中央与地方、三农与 三治的关系, 顶层设计和基层创新相结合, 构 建有利于国家安全的综合结构体系; 通过活 跃社会关系、提高社区成员嵌入性, 可以缓解 和转化基层社会累积矛盾、提高农村经济持久 活力, 进而化解中央与地方之间因目标差异造 成的 “零和博弯”, 改变国家信用投入在基层 被 “精英俘获”、导致破坏反而危害稳定的困 境 [9]。何慧丽、邱建生、高 俊、温铁军 (2014) 政府理性和村社理性是新中国成立以来的现 代化进程呈现出不同于西方的两大 “比较优 势”。政府理性反映了中国工业化的组织保障 特点。村社理性在社队企业原始积累阶段形成 “内部化处理外部性风险” 的机制, 对产业资 本扩张阶段的经济危机具有 “软着陆” 载体 作用。最后得出结论对中国这两大比较优势之 对立统一关系及其变化的研究, 有利于中国软 
实力之内涵性提升, 为我们说明了这两种理性 在过去的重要性以及未来意义 [10]。

国内有很多学者分别对企业面临严重的 冲击、农民工失业以及再就业进行了理论分 析, 国家采取了扩大内需的政策, 进行基础设 施建设和家电下乡来使得中国走出危机, 各角 度分析对经济现象和理论研究都具有重要意 义。本文试着结合这些研究角度综合分析产生 效果, 分析农村的重要意义, 从农村发展角度 分析中国应对突发外部风险的能力, 提出建议 保持这种能力。

\section{2008 年经济危机对中国造成的影响}

2008 年 9 月国际经济危机 [11]全面爆发, 中国经济增速快速回落, 出口出现负增长, 这 场突如其来危机使中国经济短期出现剧烈波 动。如图 1 所示。

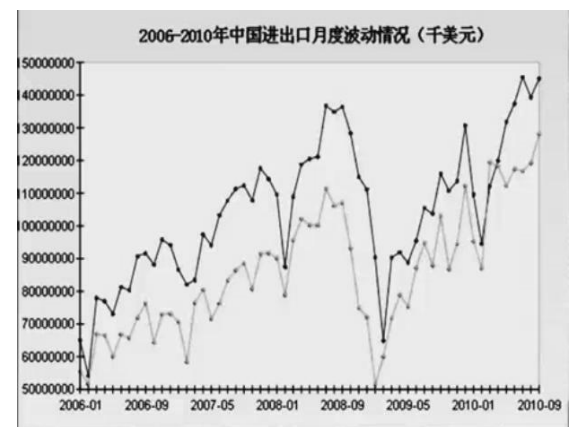

图 1. 2006-2010 年中国进出口月度波动情况（千 美元）

出口出现的大幅下降造成到 2008 年底中 国中小企业歇业、停产以及倒闭达 $7.5 \%$, 破 产企业至少达 50 万家, 虽然经济危机对中小 企业的伤害是最大的, 但是也造成上市企业收 入降到利润的拐点。中国几乎所有工业品都是 世界第一产量, 国外无市场的情况下, 中国出 现了大量过剩, 其中包含: 冰箱、洗衣机、电 视机、手机等诸多品类的工业品。

经济危机使得大量农民工失业。2008 年 10 月份开始严峻的经济形势加速了农民工返 乡, 截至 2008 年底, 我国返乡农民工总计为 7000 万人左右, 约占外出农民工总量的 50\%（见表 1)。其中, 第四季度各月返乡的农民 工占返乡总数的比例分别为 $18.2 \% 、 27.3 \%$ 和 $25.1 \%$, 扣除 11 月份和 12 月份可能因回家过年
返乡的影响, 那么因金融危机的影响而失业返 乡的农民工数量达 3327 万人左右。在受金融 危机冲击比较严重的制造业和建筑业中, 外出 农民工的返乡比例高达 $46.2 \%$ 和 $73.3 \%$, 明显 高于全国各行业的平均水平 (国家统计 局, 2009)。

\begin{tabular}{|l|l|l|}
\multicolumn{3}{|c|}{ 表 1. 2008 年农民工返乡情况统计一览表 } \\
\hline 季度 & $\begin{array}{l}\text { 返 乡人 数 } \\
\text { (万人) }\end{array}$ & $\begin{array}{l}\text { 占返乡总数比 } \\
\text { 例 (\%) }\end{array}$ \\
\hline 第一 & 101 & 1.44 \\
\hline 第二 & 592 & 8.46 \\
\hline 第三 & 1361 & 19.44 \\
\hline 第四 & 4945 & 70.65 \\
\hline
\end{tabular}

资料来源：国家统计局. 农民工监测调查报告. 2009 年 2 月

2008 年全年国内生产总值 300670 亿元, 比上 年增长 $9.0 \%$ 。分季度看, 一季度增长 $10.6 \%$, 二季度增长 $10.1 \%$, 三季度增长 $9.0 \%$, 四季度 增长 $6.8 \%$ 。进出口全年保持平稳较快增长, 四季度增速回落较多。全年进出口总额 25616 亿美元, 比上年增长 $17.8 \%$ 。其中, 出口 14285 亿美元, 增长 $17.2 \%$; 进口 11331 亿美元, 增 长 $18.5 \%$ 。进出口相抵, 贸易顺差 2955 亿美 元, 比上年增加 328 亿美元。受国际市场需求 萎缩、国际初级产品大幅下跌等因素影响, 四 季度进口同比下降 $8.8 \%$, 出口同比增长 $4.3 \%$ 。 (国家统计局) 对外贸易依存度直观看一下经 济危机对中国经济造成的波动。如图 2 所示。 图 2. 1978- 2015 年中国外贸依存度及世界贸易依 存度变化趋势

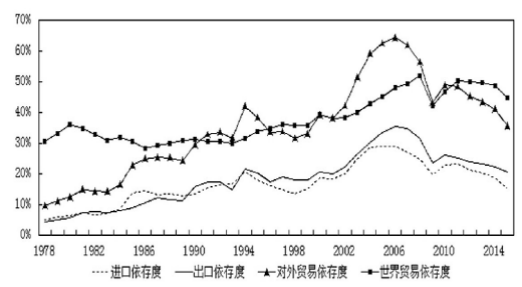

图 2 资料来源: 《中国统计年鉴》、世界银行发展指 标数据库

企业生产过剩没有市场、全国失业严重以 及 2008 下半年经济危机爆发出口严重受挫, 国际和国内都预期中国经济面临硬着陆的风 险。 


\section{2008 年经济危机的渡过和政策分析}

经济危机发生以后, 各国政府以及欧盟领 导人均迅速制定救市措施，但是各国经济表现 仍不佳, 直至现在全球经济依然低迷, 经济增 长信心不足。如表 2 所示。

表 2. 全世界历年主要国家和地区经济增长率 统计 (2006-1012)

\begin{tabular}{|c|c|c|c|c|c|c|c|c|}
\hline 年分 & 世界 & 中国 & 美国 & 欧元区 & 日本 & 巴西 & 印度 & 俄罗斯 \\
\hline 2006 & 5.1 & 12.7 & 2.7 & 3.4 & 1.7 & 4 & 9.6 & 8.2 \\
\hline 2007 & 5 & 14.2 & 1.9 & 3 & 2.2 & 6.1 & 9.3 & 8.5 \\
\hline 2008 & 2.4 & 9.6 & -0.3 & 0.3 & -1.1 & 5.2 & 6.7 & 5.3 \\
\hline 2009 & -1.5 & 9.2 & -3.1 & -4.2 & -5.5 & -0.3 & 8.6 & -7.8 \\
\hline 2010 & 4.5 & 10.6 & 2.4 & 1.8 & 4.7 & 7.5 & 9.3 & 4.3 \\
\hline 2011 & 3.2 & 9.5 & 1.8 & 1.5 & -0.5 & 2.7 & 6.2 & 4.3 \\
\hline 2012 & 3.2 & 7.7 & 2.2 & -0.6 & 1.9 & 0.9 & 5 & 3.4 \\
\hline \multicolumn{7}{|c|}{ 资料来源:国际货币基金组织数据库. } \\
\hline \multicolumn{7}{|c|}{} \\
\hline \multicolumn{7}{|c|}{}
\end{tabular}

中国和世界经济相比却出现了 V 形反弹。 国务院新闻办公室于 2010 年 1 月 21 日举行新 闻发布会, 国家统计局局长马建堂介绍 2009 年国民经济运行情况, 全年国内生产总值 335353 亿元, 按可比价格计算, 比上年增长 8. $7 \%$, 增速比上年回落 0.9 个百分点。分季度 看, 一季度增长 $6.2 \%$, 二季度增长 $7.9 \%$, 三 季度增长 $9.1 \%$, 四季度增长 $10.7 \%$ 。全球经济 出现大幅衰退的情况下, 中国经济为什么出现 半年反弹? 每个经济现象的发生都有成千上 万个经济变量, 本文主要以农村视角分析, 主 要从解决企业严重生产过剩无市场以及化解 3400 多万失业两个方面解释中国走出经济危 机。

\section{1 四万亿救市计划和新农村建设吸纳了大 量的劳动力}

2008 年 11 月 5 日, 国务院总理温家宝主 持召开国务院常务会议, 研究部署进一步扩大 内需、促进经济平稳较快增长的措施。出台了 大量相关政策: 主要有加快建设保障性安居工 程, 加快农村基础设施建设, 加快铁路、公路 和机场等重大基础设施建设, 加快医疗卫生、 文化教育事业发展（建校卫生室和医院）, 加 强生态环境建设 (处理污水和垃圾场), 加快 地震灾区灾后重建各项工作。这 4 万亿救市计 划分两年投入。基础设施建设还有 2006 年开 始新农村建设每年投入 7000 亿的投资, 进行 公路、电网和供水改造, 这两项就有近 3 万亿
的投资。经过专家测算每万亿可带动就业 1500 万, 需求的劳动力在 4500 万左右, 3327 万失 业和新增就业就可以化解, 新农村建设从 2004 年开始, 需求过大导致用工荒连续多年, 直到 2008 年经济危机出现大量失业用工荒才得以 缓解, 这由于政策和战略的调整。在国际经济 形势低迷的情况下, 中国却从 2009 年下半年 又出现用工荒, 因为政策重点支持农村基础设 施建设, 大量农民工在家门口就业, 这也解释 了为什么大量农民工回流农村。

\section{2 这种大规模的政策性投资带动带动了工 业复苏}

2009 年经济增长分产业看, 第一产业增 加值 35477 亿元, 增长 $4.2 \%$; 第二产业增加 值 156958 亿元, 增长 $9.5 \%$; 第三产业增加值 142918 亿元, 增长 $8.9 \%$ 。第二产业增长最快, 因为大规模基础设施建设的投资对实体工业 拉动最大。

\section{3 除了工业对日常消费品拉动明显}

商务部和财务部制定的家电下乡政策的 实施, 消化大量生活消费品, 大大缓解了企业 滞销的困境。这样企业才有可能进行产业升级 以及改变生产规模, 避免了大量的企业破产和 倒闭, 尤其是中国的一些知名企业。商务部和 财政部预测, 2008 年财政补贴家电下乡资金 将达到 104 亿元, 累计拉动消费 9200 亿元。 2010 年通过政策刺激的家电销售额近 3000 亿 元, 2011 年预计为 4200 亿元。巨大的市场爆 发力让国内家电企业享受到了前所未有的销 售盛宴, 包括海尔、格力、海信、美的、创维 等家电企业均在其列。农村这个政策为中国保 存了大量优秀企业。

\section{5. 农村对走出经济危机的作用}

中国 2008 年渡过如此严重的经济危机, 农村发挥了重要的作用, 但是农村的重要性到 底在哪里? 经历百年不遇的经济危机, 农村的 重要性就是中国面临这样的巨大危机安然度 过并解决严重生产过剩以及 3400 万失业。

\section{1 农村对于中国经济未来发展具有重要作 用}

2006 年开始提出新农村建设时, 很多学 
者和经济学家提出强烈反对: 中国现在发展资 源不足, 把有限资源投入到广大的农村是非常 不理性的, 公共资源在农村回收成本慢用量少 维护成本大难度高, 而且很多是无法回收成本 的。但是突然国际市场不景气, 中国启动庞大 的农村市场是需要进行大量的前期投资, 家电 下乡项目正是由于农村大规模的电网、水以及 公路的提前改造完成才可以能成功, 大型工业 品如汽车在农村迅速打开市场才有可能。因为 有水网、电网改造, 家电在农村才有市场, 公 路网改造汽车才有可能在农村使用。中国新农 村建设取得了巨大的成果，中国农村通电 $98 \%$ 以上, 通水 $92 \%$ 以上, 通路 $95 \%$ 以上。正是基 于基础设施的不断完善, 农村的市场才打开, 对于政府、企业和普通百姓都是共赢的, 由于 中国大多数企业是处于农村市场这个阶段, 这 样的企业只有生存才有可能进行产业升级和 创新, 因为技术研发是需要资金和时间的。只 有大规模的基础设施完成才可以启动农村巨 大的市场, 打开众多产品消费市场, 这样形成 规模效应从而大大降低水电服务成本、公路维 护成本, 近而带动农村的发展, 提高广大农村 人的生活水平, 收入提高进一步促进消费市场 不断扩大, 中国经济从而实现平稳快速增长, 中国经济本身就可形成良性循环, 这对中国经 济未来发展意义重大。

\section{2 农村对中国社会长期稳定具有不可替代 的作用}

2008 年经济危机发生时中国农业人口 7 亿多, 即使到 2017 年也有近 5.8 亿, 农村组 织的稳定是中国可以度过经济危机的重要原 因, 中国农村可以稳定大量人口, 即使 2008 年遇到百年一遇的经济危机, 短期大量的人口 也可以回流农村。与世界各国相比, 中国具有 维护社会稳定基础的农村。西方经济学的逻 辑, 工业和现代化起步农村就应该衰败, 为国 家现代化提供大量的劳动力, 正常情况下这种 逻辑是对的, 但是遭遇经济危机就会造成大量 失业, 社会出现动荡, 经济发展也就无从谈起 了。试想一下, 即使以现在农村人口规模 5.8 亿来算, 减去外出打工的 2017 年国家统计局 公布的 2.8 亿, 还有 3 亿人无法安排就业。如 果依据西方经济学的逻辑农村衰败, 现在就业 形势本来就非常严峻, 还需要解决 3 亿农村人
口就业, 这样的结果是国家发展所不能承受 的。实际农村对于中国的稳定作用不仅体现在 稳定平时的 3 亿农村人口, 还有遇到经济危机 和外部风险时可以稳定 2.8 亿打工人口, 这就 是农村对中国社会长期稳定的战略意义。

\section{3 农村对未来遇到不可控风险的化解具有 重要意义}

中国外部环境越来越复杂, 世界局势局部 动荡。首先 2018 年 4 月中美贸易摩擦问题, 对全球股市造成短期的大幅波动; 美英法对叙 利亚的精准打击以及朝鲜宣布停止核试验和 对外开放, 这些是短短一个月发生的大事件, 这些对世界各个国家经济发展影响巨大。其 次, 中国经济和综合国力迅速提升, 让世界各 国和周边国家感到严重的威胁, 既加剧中国周 边的不稳定性又增加了 “中国威胁论” 市场, 中国遭遇外部不可预期风险大大增加了。最 后, 中国能源、原材料的进口越来越多来自全 球不稳定地区以及三分之一以上粮食依靠外 部进口, 这些都是我们不可以掌控和回避的。 那么农村对中国渡过 2008 年经济危机的作 用, 这种作用对未来抵御各种不确定风险依然 具有重要意义。

\section{6. 提高抵御风险能力建议}

\section{1 意识上对农村的重要性要有清醒认识}

在现在西方经济学思想大行其道的背景 下, 中国整个社会应该充分认识到农村的重要 性, 不能让农村衰败, 这可以确保中国具有稳 定基础和快速增长能力, 经济的发展是基础, 这对中国实现的全面建成小康社会和社会主 义现代化强国均有重要意义。

\section{2 应当继续加强对农村的投入}

这种投入的意义是持久的, 形成良性循环 以后, 对中国的社会稳定可以起到基础的稳定 器作用, 正常情况下可以稳定五分之一的人 口, 在遇到不确定风险时, 稳定的人数在一半 左右, 这对国家安全 [12] 也具有重要战略意 义，因此应当继续加强对农村的投入。

\section{3 不断补足农村发展短板和减少农村不稳 定因素}

在国际形势日益复杂的今天, 中国面对外 
部不可预期风险的可能性大大增加, 未雨绸缪 现在就应该加强补足农村发展短板和减少农 村不稳定因素。这样面对突发风险, 我们才具 有渡过和抵御这种危机的能力, 我们要不断加 强和保持这种能力。

\section{Acknowledgements}

Fund support: This article obtains the Yunnan province science and technology project surface project (2017FB103), the Yunnan provincial philosophy social science planning project (YB2016016), the Yunnan Normal University "Dengfeng root" excellent scientific research innovation team construction project, the China Post Doctoral science fund support project (2017M623079), the Yunnan Normal University $\mathrm{PhD}$ scientific research start Funding for the project.

\section{致谢}

基金资助: 本文获得云南省科技计划面上项目 (2017FB103), 云南省哲学社会科学规划项目 (YB2016016), 云南师范大学 “登峰扎根” 优 秀科研创新团队建设项目, 中国博士后科学基 金资助项目 (2017M623079), 云南师范大学博 士科研启动项目的资助。

\section{参考文献}

[1] Dean K W, Jacob K W. A new risk management model. Journal of Risk Analysis and Crisis Response, December 2012, 2: 233-251.

[2] 马永强,孟子平. 金融危机冲击、企业风 险缓冲与政府政策选. 会计研究, 2009, (07):50-56+96.

[3] 张佳,张宏. 经济危机下农村劳动力转 移的路径选择. 理论导刊, 2009, (04):60-61+64.

[4] 张车伟,王智勇. 全球金融危机对农民 工就业的冲击一一影响分析及对策思 考. 中国人口科学, 2009, (02): 16-25+ 111.

[5] 叶冬松. 以科学发展观为指导, 积极探 索新形势下扩大内需的有效途径和方
式. 中国浦东干部学院学报, 2009,3(03):49-54.

[6] 杨帅, 董篵丹, 温铁军. 农村基础设施长 效投入的问题、经验与对策. 中州学刊, 2014, (06):50-56.

[7] 马川. “家电下乡” 后引发的思考. 法 制与社会, 2009(12):278.

[8] 温铁军. 中国的经济危机软着陆与 “三 农”政策. 华夏星火, 2009(05):30-31.

[9] 董䈗丹,梁汉民, 区吉民,温铁军. 乡村治 理与国家安全的相关问题研究——新 经济社会学理论视角的结构分析. 国 家行政学院学报, 2015(02):79-84.

[10] 何慧丽, 邱建生, 高俊, 温铁军. 政府理性 与村社理性:中国的两大 “比较优势”. 国家行政学院学报, 2014(06):39-44.

[11] Francesca E. Individual, community and societal effects of the global financial crisis: a bioecological model. Journal of Risk Analysis and Crisis Response, 2014, 4: 203-213.

[12] Salvi O, Delsinne S. Biogas - a European perspective on safety and regulation. Journal of Risk Analysis and Crisis Response, 2011 1(1): 1-20. 